\title{
Recent Advances in Pediatric Acute Respiratory Distress Syndrome (PARDS)
}

\author{
Rebecca F. Hough ${ }^{1}$
}

Published online: 12 October 2017

(C) Springer Science+Business Media, LLC 2017

\begin{abstract}
Purpose of Review The purpose of this review is to summarize the recent literature on pediatric acute respiratory distress syndrome (PARDS). This review will focus on, but not be limited to, literature using the recent definition of PARDS established by the Pediatric Acute Lung Injury Consensus Conference (PALICC) group in 2015.

Recent Findings Mortality rates for PARDS have recently decreased to $10-15 \%$. Clinical trials in PARDS have (1) emphasized the relative importance of early oxygenation in predicting mortality; (2) suggested a role for protocolized sedation in patients managed with extracorporeal membrane oxygenation (ECMO); (3) found no mortality benefit to highfrequency oscillatory ventilation (HFOV), exogenous surfactant, or corticosteroids; and (4) suggested biomarkers and whole exome sequencing as methods for personalizing management. Recent laboratory studies have suggested differences in responsiveness to high tidal volume injury in juvenile rodents.

Summary The near future of PARDS management could include earlier risk stratification of patients by (1) oxygenation within $24 \mathrm{~h}$ of PARDS diagnosis and (2) use of biomarkers and subphenotypes. Despite challenges in performing clinical trials in children, the PALICC definition presents an opportunity to explore these and more research questions in PARDS separately from adult cohorts.
\end{abstract}

This article is part of the Topical Collection on Intensive Care Medicine

Rebecca F. Hough

rft2106@cumc.columbia.edu

1 Department of Pediatrics, Columbia University College of Physicians and Surgeons, 3959 Broadway, CHN 10-24, New York, NY 10032, USA
Keywords Acute lung injury · ARDS $\cdot$ Pediatrics $\cdot$ Berlin definition $\cdot$ PARDS $\cdot$ PALICC

\section{Introduction and Definition}

Adult respiratory distress syndrome was first described in 1967 to differentiate it from respiratory distress syndrome (RDS) described in preterm neonates, with which it shared features of surfactant dysfunction, atelectasis, and hyaline membranes in alveoli $[1,2]$. Ashbaugh and colleagues described the acute onset of tachypnea and hypoxemia, with loss of compliance and infiltrations on chest radiography, but did not present a formal definition.

In 1994, the American-European Consensus Conference (AECC), acknowledging that the syndrome also occurred in children, redefined the adult respiratory distress syndrome as the acute respiratory distress syndrome (ARDS). The AECC described criteria that allowed for a definition of ARDS for research purposes (Table 1). These criteria included (1) acute onset; (2) ratio of $\mathrm{PaO}_{2} / \mathrm{FiO}_{2} \leq 200$ for ARDS and $\leq 300$ for acute lung injury (ALI), regardless of PEEP; (3) bilateral infiltrates on chest radiograph; and (4) pulmonary artery wedge pressure of $\leq 18$ if measured, or no evidence of left atrial hypertension [3].

The ARDS definition was again modified in 2012 when the Berlin definition was proposed. The Berlin definition clarified acute onset to within 1 week of a known insult. It eliminated ALI, dividing ARDS into mild $\left(200<\mathrm{PaO}_{2} / \mathrm{FiO}_{2} \leq 300\right.$, PEEP or CPAP $\geq 5)$, moderate $\left(100<\mathrm{PaO}_{2} / \mathrm{FiO}_{2} \leq 200\right.$, PEEP $\geq 5)$, and severe $\left(\mathrm{PaO}_{2} / \mathrm{FiO}_{2} \leq 100, \mathrm{PEEP} \geq 5\right)$ categories. It defined the chest imaging findings as bilateral opacities on radiograph or computed tomography scan. The Berlin definition allowed for left atrial hypertension, but the degree of respiratory failure could not be fully explained by heart failure 
Table 1 Evolution of ARDS definition in pediatrics

\begin{tabular}{|c|c|c|c|}
\hline & AECC [3] & Berlin [4] & PALICC $[5 \bullet \bullet]$ \\
\hline Age & & & Excludes perinatal-related lung disease \\
\hline Timing & Acute onset & $\begin{array}{l}\text { Within } 1 \text { week of known clinical } \\
\text { insult, or new or worsening } \\
\text { respiratory symptoms }\end{array}$ & Within 7 days of known clinical insult \\
\hline $\begin{array}{l}\text { Origin } \\
\text { of edema }\end{array}$ & $\begin{array}{l}\text { PAWP } \leq 18 \mathrm{mmHg} \text { when } \\
\text { measured, or no clinical } \\
\text { evidence of left atrial } \\
\text { hypertension }\end{array}$ & $\begin{array}{l}\text { - Respiratory failure not fully } \\
\text { explained by cardiac failure } \\
\text { or fluid overload } \\
\text { - Need objective assessment } \\
\text { (e.g., echocardiogram) to } \\
\text { exclude hydrostatic edema if no } \\
\text { risk factor present }\end{array}$ & $\begin{array}{l}\text { Respiratory failure not fully } \\
\text { explained by cardiac failure } \\
\text { or fluid overload }\end{array}$ \\
\hline $\begin{array}{l}\text { Chest } \\
\text { imaging }\end{array}$ & $\begin{array}{l}\text { Bilateral infiltrates } \\
\text { on frontal CXR }\end{array}$ & $\begin{array}{l}\text { Bilateral opacities on CXR or CT, } \\
\text { not fully explained by effusions, } \\
\text { lobar/lung collapse, or nodules }\end{array}$ & $\begin{array}{l}\text { Chest imaging findings of new infiltrate(s) } \\
\text { consistent with acute pulmonary } \\
\text { parenchymal disease }\end{array}$ \\
\hline \multicolumn{4}{|l|}{ Oxygenation } \\
\hline Severe & $\begin{array}{l}\text { ARDS: } \mathrm{PaO}_{2} / \mathrm{FiO}_{2} \leq 200 \mathrm{mmHg} \\
\quad \text { (regardless of PEEP) }\end{array}$ & $\begin{array}{l}\mathrm{PaO}_{2} / \mathrm{FiO}_{2} \leq 100 \mathrm{mmHg} \\
\text { with PEEP } \geq 5 \mathrm{~cm} \mathrm{H}_{2} \mathrm{O}\end{array}$ & $\mathrm{OI} \geq 16$, or $\mathrm{OSI}^{\mathrm{b}} \geq 12.3$ \\
\hline Moderate & & $\begin{array}{l}100 \mathrm{mmHg}<\mathrm{PaO}_{2} / \mathrm{FiO}_{2} \\
\quad \leq 200 \mathrm{mmHg} \text { with PEEP } \\
\geq 5 \mathrm{~cm} \mathrm{H}_{2} \mathrm{O}\end{array}$ & $8 \leq \mathrm{OI}<16$, or $7.5 \leq \mathrm{OSI}<12.3$ \\
\hline Mild & $\begin{array}{l}\text { ALI: } \mathrm{PaO}_{2} / \mathrm{FiO}_{2} \leq 300 \mathrm{mmHg} \\
\quad \text { (regardless of PEEP) }\end{array}$ & $\begin{array}{l}200 \mathrm{mmHg}<\mathrm{PaO}_{2} / \mathrm{FiO}_{2} \\
\quad \leq 300 \mathrm{mmHg} \text { with } \mathrm{PEEP} \geq 5 \mathrm{~cm} \\
\mathrm{H}_{2} \mathrm{O}\end{array}$ & $4 \leq \mathrm{OI}<8$, or $5 \leq \mathrm{OSI}<7.5$ \\
\hline $\begin{array}{l}\text { Non-invasive } \\
\text { ventilation }\end{array}$ & & $\begin{array}{l}\text { Mild: } 200 \mathrm{mmHg}<\mathrm{PaO}_{2} / \mathrm{FiO}_{2} \\
\quad \leq 300 \mathrm{mmHg} \text { with } \mathrm{CPAP} \geq 5 \mathrm{~cm} \\
\mathrm{H}_{2} \mathrm{O}\end{array}$ & $\begin{array}{l}\text { No severity stratification: } \\
\mathrm{PaO}_{2} / \mathrm{FiO}_{2} \leq 300 \text { or } \mathrm{SpO}_{2} / \mathrm{FiO}_{2}{ }^{\mathrm{a}} \leq 264 \\
\text { Full face-mask bi-level ventilation, } \\
\quad \text { or CPAP } \geq 5 \mathrm{~cm} \mathrm{H} \mathrm{H}_{2} \mathrm{O}\end{array}$ \\
\hline $\begin{array}{l}\text { Special } \\
\text { populations }\end{array}$ & & & $\begin{array}{l}\text { Cyanotic heart disease, chronic lung disease, } \\
\text { left ventricular dysfunction must meet } \\
\text { criteria above and oxygenation defect must not be } \\
\text { explained by underlying illness }\end{array}$ \\
\hline
\end{tabular}

$P A W P$ pulmonary artery wedge pressure, $C X R$ chest radiograph, $C T$ computed tomography scan, $C P A P$ continuous positive airway pressure, $O I$ oxygenation index

${ }^{\text {a }}$ To calculate $\mathrm{SpO}_{2} / \mathrm{FiO}_{2}$ when $\mathrm{PaO}_{2}$ is not available, wean $\mathrm{FiO} 2$ to maintain $\mathrm{SpO} 2 \leq 97 \%$

${ }^{\mathrm{b}}$ To calculate OSI when $\mathrm{PaO} 2$ is not available, wean FiO2 to maintain $\mathrm{SpO} 2 \leq 97 \%\left(\mathrm{OSI}=\left[\mathrm{FiO}_{2} \times \text { mean airway pressure } \times 100\right] / \mathrm{PaO}\right)_{2}$

or fluid overload. The Berlin definition had improved predicted validity for mortality in adults compared to the AECC definition [4].

In 2014, the Pediatric Acute Lung Injury Consensus Conference (PALICC) group originated from the Pediatric Acute Lung Injury and Sepsis Investigators (PALISI) Network to define pediatric ARDS or PARDS. The PALICC definition kept the requirements of within 1 week of a known insult, and respiratory failure not fully explained by heart failure or fluid overload. The only age criterion was to exclude patients with perinatal-related lung disease; no upper age limit was proposed. The requirement for bilateral infiltrates on chest radiograph was eliminated, with PALICC requiring a new infiltrate or infiltrates consistent with acute pulmonary parenchymal disease. For patients receiving invasive mechanical ventilation, PARDS was defined by oxygenation index (OI) or oxygen saturation index (OSI), to better define compliance defects. The use of OSI eliminated the requirement of obtaining an arterial blood gas, a common challenge in the pediatric population. Thus, mild PARDS was defined as $4 \leq$ OI $<8$, moderate PARDS as $8 \leq \mathrm{OI}<16$, and severe PARDS as $\mathrm{OI} \geq 16$, with corresponding OSI ranges (Table 1). PARDS diagnosis without severity stratification was permitted in patients receiving non-invasive mechanical ventilation with full facemask bi-level ventilation or CPAP $\geq 5 \mathrm{~cm} \mathrm{H}_{2} \mathrm{O}$, with $\mathrm{PaO}_{2} / \mathrm{FiO}_{2} \leq 300$ or $\mathrm{SaO}_{2} / \mathrm{FiO}_{2} \leq 264$. PARDS could also be diagnosed in patients with cyanotic heart disease, chronic lung disease, and left ventricular dysfunction with modifications. A definition of patients "at risk for PARDS" was also included with an aim to better understand disease progression and to potentially prevent PARDS in the future $[5 \bullet \bullet$.

This is not meant to be an exhaustive review of PARDS clinical trials and current management. Rather, recent literature in PARDS using the Berlin and PALICC definitions will be highlighted (Table 2). Several studies using the AECC definition or respiratory failure as inclusion criteria will also 
Table 2 Clinical studies using Berlin and/or PALICC definitions in children

\begin{tabular}{|c|c|c|c|}
\hline Study & Use of Berlin definition & Use of PALICC definition & Brief summary \\
\hline Yehya 2015 [6] & $\begin{array}{l}\text { Met criteria } \\
\text { (AECC used as inclusion screen) }\end{array}$ & Met criteria & $\begin{array}{l}\text { - Observational, single-center study } \\
\text { - Corticosteroid exposure for }>24 \mathrm{~h} \text { with } \\
\text { mechanical ventilation was associated } \\
\text { with fewer VFD and longer duration of } \\
\text { ventilation in survivors }\end{array}$ \\
\hline Yehya 2015 [7] & $\begin{array}{l}\text { Met criteria } \\
\quad \text { (AECC used as inclusion screen) }\end{array}$ & No & $\begin{array}{l}\text { - Prospective, observational, single-center study } \\
\text { - } \mathrm{PaO}_{2} / \mathrm{FiO}_{2} \text { and } \mathrm{OI} 24 \mathrm{~h} \text { after meeting ARDS } \\
\text { criteria stratified mortality, VFD, and duration } \\
\text { of ventilation in survivors }\end{array}$ \\
\hline Bateman 2016 [8] & No & $\begin{array}{l}\text { Stratified by PALICC } \\
\text { in subgroup analysis }\end{array}$ & $\begin{array}{l}\text { - Secondary propensity score analysis } \\
\text { - HFOV within 24-28 h of endotracheal intubation } \\
\text { was associated with longer duration of mechanical } \\
\text { ventilation and increased mortality compared to } \\
\text { conventional mechanical ventilation and/or late use of HFOV }\end{array}$ \\
\hline Guo 2016 [9•] & No & Used as inclusion screen & $\begin{array}{l}\text { - Retrospective, observational study } \\
\text { - Increased duration of mechanical ventilation in } \\
\text { children receiving HFOV compared to conventional } \\
\text { mechanical ventilation }\end{array}$ \\
\hline Yehya 2016 [10] & $\begin{array}{l}\text { Used as inclusion } \\
\text { screen }\end{array}$ & Met criteria & $\begin{array}{l}\text { - Prospective, observational, single-center study } \\
\text { - Levels of Ang-2 and sRAGE were associated with } \\
\text { PICU mortality }\end{array}$ \\
\hline Yehya 2016 [11] & $\begin{array}{l}\text { Used as inclusion } \\
\text { screen }\end{array}$ & Met criteria & $\begin{array}{l}\text { - Prospective, observational, single-center study } \\
\text { - Plasma nucleosome levels correlated with mortality, } \\
\text { non-pulmonary organ failures, and worsening } \mathrm{PaO}_{2} / \mathrm{FiO}_{2}\end{array}$ \\
\hline Schneider 2017 [12] & No & $\begin{array}{l}\text { Stratified by PALICC } \\
\text { in subgroup analysis }\end{array}$ & $\begin{array}{l}\text { - Secondary analysis } \\
\text { - ECMO patients had more sedation withdrawal then } \\
\text { matched controls with moderate to severe PARDS }\end{array}$ \\
\hline Yehya 2017 [13] & $\begin{array}{l}\text { Met criteria } \\
\text { (AECC used as inclusion screen) }\end{array}$ & No & $\begin{array}{l}\text { - Prospective, observational cohort study } \\
\text { - } \mathrm{PaO}_{2} / \mathrm{FiO} 2 \text { and } \Delta \mathrm{PaO}_{2} / \mathrm{FiO}_{2} 24 \text { h after ARDS onset } \\
\text { correlated with mortality }\end{array}$ \\
\hline
\end{tabular}

AECC American-European Consensus Conference, PALICC Pediatric Acute Lung Injury Consensus Conference, VFD ventilator-free days, HFOV highfrequency oscillatory ventilation, Ang-2 angiopoietin-2, $s R A G E$ soluble receptor for advanced glycation end products, $P I C U$ pediatric intensive care unit, $E C M O$ extra corporeal membrane oxygenation

be reviewed, as few studies have been published to date using the Berlin and PALICC definitions. Finally, we will discuss recent developments in the study of juvenile animal models of PARDS.

\section{PARDS vs. ARDS}

Infants are born with $\sim 50$ million alveoli which increase to 200-300 million in the adult lung. The majority of alveolarization occurs during the first 2 years of life. Pulmonary microvasculature maturation, including the formation of a single capillary from two in the alveolar septum, continues for 2-3 years. By age 3, the human lung resembles that of a "small adult" [14-16]. A large number of PARDS cases occur in the first 2-3 years of life [17]. The continuing development and growth potential could aid in resolution and regeneration following PARDS, but could also place the pediatric lung at risk of damage lasting into adulthood [14].
The incidence of PARDS is $2-12.8$ per 100,000 personyears, compared to 17.9-81 per 100,000 person-years in adult ARDS. While pneumonia is the most common cause of PARDS, sepsis is the most common cause of ARDS in adults. In children, viral pneumonias are more prominent than in adults $[14,17,18]$. Physiologically, the innate immune system of children differs from that of adults. Neutrophils and macrophages have limited chemotactic ability in children. In vitro, neonatal neutrophils, monocytes, and whole cord blood show decreased production of tumor necrosis factor (TNF)- $\alpha$, IL$1 \beta$ interleukin (IL)-1 $\beta$, and IL-12 in response to lipopolysaccharide (LPS) [19]. These factors may contribute to an increase in pneumonia as a cause of PARDS.

Children with PARDS are managed differently from adults with ARDS, with a relative decrease in the use of invasive monitoring (e.g., arterial lines), increase in non-invasive mechanical ventilation, increase of high-frequency oscillatory ventilation (HFOV), and use of lower PEEP [17, 20]. Younger children and infants may also receive increased sedation compared to adults, possibly resulting in decreased 
early mobility, increased delirium, and increased rates of neuropathy and myopathy [21].

\section{Oxygenation as a Predictor of Mortality}

The mortality rate for children with PARDS is less than that of adults with ARDS [5••, 13]. However, the burden of PARDS in the pediatric intensive care unit (PICU) is significant, as $8.3 \%$ of all mechanically ventilated patients in the PICU meet the AECC definition of ARDS [17, 20]. Children with PARDS are a heterogeneous population, and negative prognostic risk factors include preexisting immunodeficiency, multisystem organ failure, non-pulmonary sepsis, lower $\mathrm{PaO}_{2} / \mathrm{FiO}_{2}$, and higher OI $[7,16,22,23]$. Indeed, a minimum $\mathrm{PaO}_{2} / \mathrm{FiO}_{2}$ less than 53 predicts a risk of death greater than $70.5 \%$, and a maximum OI greater than 53.5 predicts a risk of death greater than $80 \%[22,24]$.

Clinical studies in the era of the Berlin and PARDS definitions show a decreasing mortality rate from 18 to $35 \%$ to 10 $15 \%[5 \bullet, 13,25]$. The ability of the Berlin and PALICC definitions to discriminate mortality in children was addressed in a prospective, observational, single-center trial of 283 children who were mechanically ventilated and met the Berlin definition for ARDS. The mortality rate in this trial was $13 \%$. The authors found that both $\mathrm{PaO}_{2} / \mathrm{FiO}_{2}$ and OI measured $24 \mathrm{~h}$ after meeting ARDS criteria could discriminate mortality. Using $\mathrm{PaO}_{2} / \mathrm{FiO}_{2}$, patients with severe ARDS had a mortality rate of $37 \%$, those with moderate ARDS had a mortality rate of $18 \%$, and those with mild ARDS had a mortality rate of $8 \%$ (mortality area under the curve 0.684 , $P<0.001)$. Using OI, patients with severe ARDS had a mortality rate of $28 \%$, those with moderate ARDS had a mortality rate of $16 \%$, and those with mild ARDS had a mortality rate of $9 \%$ (mortality area under the curve $0.661, P=0.002$ ) [7].

The advent of lung-protective ventilation has led to improvements in mortality in pediatric and adult patients with ARDS [26-28]. More recently, driving pressure $(\Delta \mathrm{P})$ has emerged as a predictor of mortality in adults with ARDS [29]. However, in a prospective, observational cohort study of 352 mechanically ventilated children meeting the Berlin definition of ARDS, $\mathrm{PaO}_{2} / \mathrm{FiO}_{2} 24 \mathrm{~h}$ after ARDS onset and change in $\mathrm{PaO}_{2} / \mathrm{FiO}_{2}$ over the first $24 \mathrm{~h}$ were associated with mortality in multivariable logistic regression. Peak inspiratory pressure, PEEP, driving pressure, and dynamic compliance were not associated with mortality, suggesting that oxygenation may be a better predictor of mortality in children with ARDS [13].

These findings are consistent with a 2005 study by Flori et al. [30], which suggested the initial severity of hypoxemia is more predictive of mortality in children than in adults. In the future, early identification and risk stratification of children with PARDS may present an opportunity to intervene with potential therapies before disease progression.

\section{Protocolized Sedation}

The dangers of oversedation have been recognized in adult intensive care, leading to a more diligent approach to addressing pain and sedation, including the use of sedation scales, and evaluation for and management of delirium [31]. Addressing pain and sedation in infants and children presents challenges, considering the inability to reason with younger children, and the difficulties in assessing delirium. This can create a culture of oversedation in the PICU.

The RESTORE (Randomized Evaluation of Sedation Titration for Respiratory Failure) trial examined the benefits of a protocol for the management of sedation in mechanically ventilated pediatric patients. The RESTORE trial was a large, cluster-randomized trial that enrolled a total of 2449 pediatric patients with respiratory failure in 17 intervention PICUs and 14 control PICUs [21]. The intervention PICUs used a nurseimplemented, goal-directed algorithm to guide sedation. Of note, only a subset of these patients met the PALICC definition, but several secondary analyses of PARDS patients have come of out this study. Seven hundred and fifty-three $(61.5 \%)$ of the patients in the protocol group and $764(62.4 \%)$ of the control patients receiving usual care had mild, moderate, or severe PARDS. The primary outcome, duration of mechanical ventilation, showed no difference between the two groups. No difference was observed in adverse events such as unplanned extubation, unplanned removal of invasive tubes and lines, inadequate pain and sedation management, and iatrogenic withdrawal.

One secondary analysis of the RESTORE data examined 61 patients that received extracorporeal membrane oxygenation (ECMO) for moderate to severe PARDS. This analysis showed that patients managed with ECMO had more withdrawal than matched controls with moderate to severe PARDS who were not managed with ECMO. ECMO patients that were randomized to the protocolized sedation received a lower cumulative dose of opioids than ECMO patients who received usual care, and had no observed differences in wakefulness and agitation [12]. This analysis suggests that patients receiving ECMO for PARDS are at risk for oversedation and the consequences thereof, and may benefit from a sedation protocol.

\section{High-Frequency Oscillatory Ventilation}

HFOV is mode of ventilation used to improve oxygenation through the use of high mean airway pressures and delivery of very small tidal volumes at very high rates. In 2013, two large clinical trials essentially ended the use of HFOV in 
ARDS in adults. The OSCILLATE (Oscillation for Acute Respiratory Distress Syndrome Treated Early) trial was a randomized control trial of 548 adults with new-onset moderate to severe ARDS. The HFOV group had a higher rate of in-hospital mortality (47\%), compared to the control group that received low tidal volume, high PEEP ventilation by conventional ventilator $(35 \%)$. This difference was despite similar oxygenation and compliance between the groups before HFOV was initiated. Patients receiving HFOV also received higher doses of benzodiazepines, more frequent neuromuscular blockade, and vasoactive drugs compared to controls. The trial was stopped early due to a consistent finding of increased mortality in the HFOV group, and a desire to avoid putting patients at risk with little likelihood of benefit. The OSCILLATE authors noted that studies terminated on the basis of harm are more likely to overestimate the magnitude of harm, but that HFOV was at best unlikely to decrease mortality [32]. The OSCAR (Oscillation in ARDS) trial of 795 adults with moderate to severe ARDS randomized to receive HFOV or conventional ventilation showed no difference in mortality between the two groups [33]. Thus, in adults with moderate to severe ARDS, HFOV is not beneficial and may be associated with increased mortality.

HFOV has been associated with improvements in oxygenation in children with respiratory failure and ARDS [34-36], but not an improvement in mortality [37]. Bateman and colleagues performed a secondary propensity score analysis of the RESTORE data to compare outcomes in pediatric patients receiving HFOV within 24-48 h of endotracheal intubation (early HFOV) with those receiving conventional mechanical ventilation or HFOV at a later time. Early HFOV was associated with longer duration of mechanical ventilation and an increase in mortality, when adjusted for risk quintile [8]. RESTORE patients were stratified according to PARDS severity categories. It should be noted, however, that the control group receiving conventional mechanical ventilation and/or late HFOV also included patients who were "at risk for PARDS," comprising $17 \%$ of the control group, likely biased the results against the early HFOV group.

Separately, a retrospective, observational study of 48 children with PARDS also showed increased duration of mechanical ventilation in children with PARDS (PALICC definition) who received HFOV compared to those receiving conventional mechanical ventilation. No increased risk of mortality was seen. The HFOV group showed improved $\mathrm{PaO}_{2} / \mathrm{FiO}_{2}$, OI, $\mathrm{PaCO}_{2}, \mathrm{PaO}_{2}$, but an increased PICU length of stay [9॰]. In the absence of a randomized control trial, HFOV continues to be used as a rescue therapy for PARDS.

\section{Adjunct Therapies: Surfactant and Corticosteroids}

As surfactant is both deficient and dysfunctional in PARDS, several recent studies have considered the utility of surfactant treatment [38]. Instillation of calf lung surfactant extract (calfactant) had been shown to decrease duration of mechanical ventilation and PICU length of stay in children with acute hypoxemic respiratory failure [39]. A randomized trial using bovine surfactant to treat children meeting the AECC definition for ARDS noted a brief initial improvement in $\mathrm{P} / \mathrm{F}$, but the improvement was only sustained in patients with $\mathrm{P} / \mathrm{F}>65$ [40]. A randomized blinded multicenter trial of calfactant in 153 children with ALI showed a significant decrease in inhospital mortality and decrease in OI in those receiving calfactant versus air placebo. However, no improvement in duration of mechanical ventilation, ICU length of stay, or hospital stay was observed [41].

Direct causes of ARDS are those that originate on the alveolar side of the alveolar-capillary barrier, including pneumonia and aspiration. Indirect causes of ARDS originate on the vascular side of the alveolar-capillary barrier and include sepsis and transfusion-related acute lung injury (TRALI) [42]. Recently, 110 children meeting the AECC definition for ALI and ARDS caused by direct lung injury were randomized to receive calfactant or air placebo within $48 \mathrm{~h}$ of beginning mechanical ventilation. The groups showed no difference in the primary outcome, all-cause mortality at 90 days. Indeed, the calfactant group had fewer hospital-free days at 28 days than the placebo group [43]. Both this study and its adult arm [44] were halted by the pharmaceutical sponsor for futility.

Trials examining corticosteroid use in ARDS have not suggested improvement in outcomes, and the PALICC group did not recommend corticosteroids as routine therapy for PARDS [45*0]. A single-center, observational study of 283 children meeting AECC, Berlin, and PALICC criteria for ALI/ARDS assessed the association between corticosteroid use and outcomes. Sixty percent of the patients received corticosteroids for greater than $24 \mathrm{~h}$ while being mechanically ventilated. In multivariate and propensity score adjusted analyses, corticosteroid exposure was associated with fewer ventilator-free days at 28 days and longer duration of mechanical ventilation in survivors, and not associated with a difference in mortality [6].

\section{On the Horizon in PARDS: Biomarkers, Genetics, and Subphenotypes}

In ARDS, hyperpermeability of the endothelial and epithelial barriers results in the accumulation of proteinaceous fluid in the alveolar airspace $[28,46]$. The activation of the innate and adaptive immune systems is necessary for pathogen containment and recovery from lung injury. However, dysregulation of inflammation can also contribute to the pathogenesis of ARDS [28]. The immaturity of the innate immune system in infants and young children may change the contribution of inflammation to pathogenesis, as well as contribute to 
heterogeneity in the PARDS population. Biomarkers from serum or bronchioalveolar lavage (BAL) fluid have the potential to inform our knowledge of the pathological mechanisms of PARDS, risk-stratify patients, and guide personalized therapies [47].

In a recent multicenter prospective observational cohort study of 243 pediatric patients in 5 PICUs meeting the AECC definition, plasma soluble thrombomodulin (sTM), a transmembrane protein highly expressed in alveolar endothelium, was measured within $24 \mathrm{~h}$ of ARDS diagnosis. The authors found higher levels of plasma STM in patients with ARDS resulting from indirect etiologies compared to direct etiologies $(P=0.02)$. Increased organ dysfunction, as measured by pediatric logistic organ dysfunction (PELOD) score, was noted in patients with higher sTM levels $(P<0.01)$. Finally, sTM levels were associated with increased ICU mortality $(P=0.02)[48]$, presenting a potential marker for prognostication.

Another marker of endothelial injury, angiopoietin-2 (Ang2), was also shown to associate with PARDS mortality in two recent studies. A prospective cohort study of 259 patients $<18$ years old meeting the AECC definition were enrolled, and plasma Ang-2 levels were checked on days 1 and 3 of ARDS diagnosis. Ang-2 levels were associated with PICU mortality independent of age, sex, race, and $\mathrm{PaO}_{2} / \mathrm{FiO}_{2}$ in regression analysis $(P=0.027)$. The association of elevated Ang-2 and mortality was more pronounced in a cohort of patients with a history of hematopoietic stem cell transplant $(P=0.028)$ [49]. In a single-center, prospective observational study of 82 children meeting the Berlin definition, levels of Ang-2 and soluble receptor for advanced glycation end products (sRAGE), a marker of alveolar type I epithelial cell damage, were associated with PICU mortality ( $P<0.01$ for both). Levels of both Ang-2 and sRAGE correlated with number of non-pulmonary organ failures $(P<0.001)$. In stratified analysis, Ang-2 and sRAGE were associated with mortality in ARDS resulting from direct lung injury and in immunocompetent children [10].

Recently, plasma nucleosomes were shown to associate with mortality in a single-center, prospective, observational study of 76 children meeting the Berlin definition. Nucleosomes, markers of cellular damage and chromatin degradation, were measured in plasma within $48 \mathrm{~h}$ of ARDS diagnosis. Nucleosome levels correlated with mortality $(P<0.001)$, increasing number of non-pulmonary organ failures $(P=0.009)$, and worsening $\mathrm{PaO}_{2} / \mathrm{FiO}_{2}(P=0.012)$. The association of nucleosome levels and mortality was independent of age, severity of illness, number of non-pulmonary organ failures, vasopressor score, or $\mathrm{PaO}_{2} / \mathrm{FiO}_{2}$ in regression analysis. There was no association with nucleosome levels and etiology of ARDS, nor was there an association with severity of illness as defined by Berlin or PALICC oxygenation categories [11].
Whole exome sequencing (WES) of children with severe PARDS may reveal gene defects that underlie the heterogeneity among patients. Recent WES of an otherwise healthy girl who developed severe ARDS in response to H1N1 influenza revealed a compound heterozygous null mutation in the transcription factor interferon regulatory factor 7 [50•]. In addition, WES of 96 adult ARDS patients revealed 76 potentially novel single nucleotide polymorphisms (SNPs) in 65 genes that were associated with ARDS susceptibility [51]. This technology applied to PARDS has the potential to lead to new mechanistic insights, discovery of new biomarkers, and/or patient-specific therapies (i.e., precision medicine).

A recent analysis of two large randomized controlled trials of adult ARDS patients (ARMA and ALVEOLI trials: 1022 total patients) revealed a "hyperinflammatory" subphenotype of ARDS. Patients with this subphenotype had a higher prevalence of sepsis, with higher vasopressor use, lower serum bicarbonate, and higher plasma levels of pro-inflammatory cytokines (IL-6, IL-8, and TNF- $\alpha$ ). They also had double the mortality rate. The use of high levels of PEEP in these patients was associated with lower mortality [52]. Future PARDS management may rely on the identification of subphenotypes in pediatric patients who will benefit from different treatment strategies.

\section{Juvenile Animal Studies on High Tidal Volume Ventilation}

The lack of specific therapy for PARDS highlights the need for a mechanistic understanding of lung injury that leads to PARDS. However, there remains a dearth of basic science studies examining lung injury in juvenile animals. The rat lung is slightly less mature than the human lung at birth, providing a reasonable model for postnatal lung development [15].

Sly and colleagues subjected infant (2 weeks old) PiebaldVirol-Glaxo rats to aspiration of hydrochloric acid or saline, followed by ventilation with high tidal volume with low PEEP (21 ml/kg, $1 \mathrm{~cm} \mathrm{H} 2 \mathrm{O}$ ) or low tidal volume with high PEEP ( $7 \mathrm{ml} / \mathrm{kg}, 3 \mathrm{~cm} \mathrm{H} 2 \mathrm{O}$ ). Lung injury, as measured by bronchoalveolar lavage (BAL) protein and histological lung injury scores, was no different in the groups subjected to different ventilations strategies, in contrast with studies in adult rodent lungs [53]. Separately, male RCCHan Wistar rats stratified in four different age groups - infant (15 days old), juvenile (37 days old), adult (4 months old), and elderly (19.5 months old)—were subjected to intra-tracheal LPS installation and/or high tidal volume $(15 \mathrm{ml} / \mathrm{kg})$ ventilation. Lungs were then scored histologically for lung injury, and BAL protein and IL-6 and CXCL2 levels were measured. Overall, an increase in lung injury with age was noted in response to ventilation, LPS, or both. Lung injury was more dependent on LPS 
exposure than high tidal volume ventilation. Elderly rats were more affected by high tidal volume ventilation [54]. These two studies suggest a relative protection of juvenile animals from lung injury associated with high tidal volume ventilation. Infants do have more compliant chest walls with less elastic recoil [25], but this could make infant lungs more susceptible to volutrauma associated with high tidal volume ventilation. The relative protection of juvenile animals from high tidal volume ventilation is an intriguing finding, but further mechanistic studies are needed.

\section{Conclusions}

The impact of the PALICC definition of PARDS is yet to be determined. The challenges of undertaking clinical research studies in PARDS remain substantial. However, the differences in children in etiology, management, and outcomes, and now, the very definition of PARDS, underline the need for pediatric-specific studies. The use of mortality rate as an outcome measure is nearly impossible, given the low mortality rate of PARDS $[13,25]$. The inclusion of children with chronic lung disease, congenital heart disease, and left ventricular dysfunction in the PARDS definition [5••] may increase the relative mortality of study populations, but the impact of their inclusion on population heterogeneity must be considered. The use of ventilator-free days as an outcome can be potentially complicated by the allowance of non-invasive ventilatory support in the PARDS definition [55]. There is a need for international consortia such as PALISI and the European Society of Pediatric and Neonatal Intensive Care (ESPNIC) to come together for multicenter trials to increase the numbers of enrollees [56] and avoid the common premature termination of clinical trials in children with ARDS [43, 57]. An increasing distinction between direct and indirect causes of ARDS is emerging in the literature [10, 41, 43, 48]. However, it is unclear to what extent the cellular mechanisms of direct and indirect ARDS differ. Further understanding of the pathophysiology of PARDS through (1) translational study of biomarkers, exome sequencing, and subphenotypes and (2) mechanistic studies in juvenile animals could lead to improvements in prognostication and personalized management of PARDS in the future.

\section{Compliance with Ethical Standards}

Conflict of Interest Rebecca F. Hough declares that she has no conflict of interest.

Human and Animal Rights and Informed Consent This article does not contain any studies with human or animal subjects performed by any of the authors.

\section{References}

Papers of particular interest, published recently, have been highlighted as:

- Of importance

- Of major importance

1. Ashbaugh DG, Bigelow DB, Petty TL, Levine BE. Acute respiratory distress in adults. Lancet. 1967;2(7511):319-23.

2. Thompson BT, Chambers RC, Liu KD. Acute respiratory distress syndrome. N Engl J Med. 2017;377(6):562-72. https://doi.org/10. 1056/NEJMra1608077.

3. Bernard GR, Artigas A, Brigham KL, Carlet J, Falke K, Hudson L, et al. Report of the American-European consensus conference on acute respiratory distress syndrome: definitions, mechanisms, relevant outcomes, and clinical trial coordination. Consensus Committee J Crit Care. 1994;9(1):72-81.

4. Force ADT, Ranieri VM, Rubenfeld GD, Thompson BT, Ferguson ND, Caldwell E, et al. Acute respiratory distress syndrome: the berlin definition. JAMA. 2012;307(23):2526-33. https://doi.org/ 10.1001/jama.2012.5669.

5.• Khemani RG, Smith LS, Zimmerman JJ, Erickson S, Pediatric Acute Lung Injury Consensus Conference G. Pediatric acute respiratory distress syndrome: definition, incidence, and epidemiology: proceedings from the Pediatric Acute Lung Injury Consensus Conference. Pediatr Crit Care Med. 2015;16(5 Suppl 1):S23-40. https://doi.org/10.1097/PCC.0000000000000432. PALICC Definition of PARDS.

6. Yehya N, Servaes S, Thomas NJ, Nadkarni VM, Srinivasan V. Corticosteroid exposure in pediatric acute respiratory distress syndrome. Intensive Care Med. 2015;41(9):1658-66. https://doi.org/ 10.1007/s00134-015-3953-4.

7. Yehya N, Servaes S, Thomas NJ. Characterizing degree of lung injury in pediatric acute respiratory distress syndrome. Crit Care Med. 2015;43(5):937-46. https://doi.org/10.1097/CCM. 0000000000000867.

8. Bateman ST, Borasino S, Asaro LA, Cheifetz IM, Diane S, Wypij $\mathrm{D}$, et al. Early high-frequency oscillatory ventilation in pediatric acute respiratory failure. A propensity score analysis. Am J Respir Crit Care Med. 2016;193(5):495-503. https://doi.org/10.1164/ recm.201507-13810C.

9. Guo YX, Wang ZN, Li YT, Pan L, Yang LF, Hu Y, et al. Highfrequency oscillatory ventilation is an effective treatment for severe pediatric acute respiratory distress syndrome with refractory hypoxemia. Ther Clin Risk Manag. 2016;12:1563-71. https://doi.org/ 10.2147/TCRM.S115884. Used PALICC definiton as inclusion criteria.

10. Yehya N, Thomas NJ, Meyer NJ, Christie JD, Berg RA, Margulies SS. Circulating markers of endothelial and alveolar epithelial dysfunction are associated with mortality in pediatric acute respiratory distress syndrome. Intensive Care Med. 2016;42(7):1137-45. https://doi.org/10.1007/s00134-016-4352-1.

11. Yehya N, Thomas NJ, Margulies SS. Circulating nucleosomes are associated with mortality in pediatric acute respiratory distress syndrome. Am J Physiol Lung Cell Mol Physiol. 2016;310(11): L1177-84. https://doi.org/10.1152/ajplung.00067.2016.

12. Schneider JB, Sweberg T, Asaro LA, Kirby A, Wypij D, Thiagarajan RR, et al. Sedation management in children supported on extracorporeal membrane oxygenation for acute respiratory failure. Crit Care Med. 2017; https://doi.org/10.1097/CCM. 0000000000002540.

13. Yehya N, Thomas NJ. Disassociating lung mechanics and oxygenation in pediatric acute respiratory distress syndrome. Crit Care 
Med. 2017;45(7):1232-9. https://doi.org/10.1097/CCM. 0000000000002406

14. Sapru A, Flori H, Quasney MW, Dahmer MK, Pediatric Acute Lung Injury Consensus Conference G. Pathobiology of acute respiratory distress syndrome. Pediatr Crit Care Med. 2015;16(5 Suppl 1):S6-22. https://doi.org/10.1097/PCC.0000000000000431.

15. Burri PH. Structural aspects of postnatal lung development-alveolar formation and growth. Biol Neonate. 2006;89(4):313-22. https://doi.org/10.1159/000092868.

16. Thomas NJ, Jouvet P, Willson D. Acute lung injury in childrenkids really aren't just "little adults". Pediatr Crit Care Med. 2013;14(4):429-32. https://doi.org/10.1097/PCC. 0b013e31827456aa.

17. Lopez-Fernandez Y, Azagra AM, de la Oliva P, Modesto V, Sanchez JI, Parrilla J, et al. Pediatric acute lung injury epidemiology and natural history study: incidence and outcome of the acute respiratory distress syndrome in children. Crit Care Med. 2012;40(12):3238-45. https://doi.org/10.1097/CCM. 0b013e318260caa3.

18. Zhu YF, Xu F, Lu XL, Wang Y, Chen JL, Chao JX, et al. Mortality and morbidity of acute hypoxemic respiratory failure and acute respiratory distress syndrome in infants and young children. Chin Med J. 2012;125(13):2265-71.

19. Smith LS, Zimmerman JJ, Martin TR. Mechanisms of acute respiratory distress syndrome in children and adults: a review and suggestions for future research. Pediatr Crit Care Med. 2013;14(6): 631-43. https://doi.org/10.1097/PCC.0b013e318291753f.

20. Cornfield DN. Acute respiratory distress syndrome in children: physiology and management. Curr Opin Pediatr. 2013;25(3):338 43. https://doi.org/10.1097/MOP.0b013e328360bbe7.

21. Curley MA, Wypij D, Watson RS, Grant MJ, Asaro LA, Cheifetz IM, et al. Protocolized sedation vs usual care in pediatric patients mechanically ventilated for acute respiratory failure: a randomized clinical trial. JAMA. 2015;313(4):379-89. https://doi.org/10.1001/ jama.2014.18399.

22. Flori H, Dahmer MK, Sapru A, Quasney MW, Pediatric Acute Lung Injury Consensus Conference G. Comorbidities and assessment of severity of pediatric acute respiratory distress syndrome: proceedings from the Pediatric Acute Lung Injury Consensus Conference. Pediatr Crit Care Med. 2015;16(5 Suppl 1):S41-50. https://doi.org/10.1097/PCC.0000000000000430.

23. Quasney MW, Lopez-Fernandez YM, Santschi M, Watson RS, Pediatric Acute Lung Injury Consensus Conference G. The outcomes of children with pediatric acute respiratory distress syndrome: proceedings from the Pediatric Acute Lung Injury Consensus Conference. Pediatr Crit Care Med. 2015;16(5 Suppl 1):S118-31. https://doi.org/10.1097/PCC. 0000000000000438 .

24. Erickson S, Schibler A, Numa A, Nuthall G, Yung M, Pascoe E, et al. Acute lung injury in pediatric intensive care in Australia and New Zealand: a prospective, multicenter, observational study. Pediatr Crit Care Med. 2007;8(4):317-23. https://doi.org/10.1097/ 01.PCC.0000269408.64179.FF.

25. Randolph AG. Management of acute lung injury and acute respiratory distress syndrome in children. Crit Care Med. 2009;37(8): 2448-54. https://doi.org/10.1097/CCM.0b013e3181aee5dd.

26. Amato MB, Barbas CS, Medeiros DM, Magaldi RB, Schettino GP, Lorenzi-Filho G, et al. Effect of a protective-ventilation strategy on mortality in the acute respiratory distress syndrome. N Engl J Med. 1998;338(6):347-54. https://doi.org/10.1056/ NEJM199802053380602.

27. Acute Respiratory Distress Syndrome N, Brower RG, Matthay MA, Morris A, Schoenfeld D, Thompson BT, et al. Ventilation with lower tidal volumes as compared with traditional tidal volumes for acute lung injury and the acute respiratory distress syndrome. $\mathrm{N}$
Eng1 J Med. 2000;342(18):1301-8. https://doi.org/10.1056/ NEJM200005043421801.

28. Matthay MA, Ware LB, Zimmerman GA. The acute respiratory distress syndrome. J Clin Invest. 2012;122(8):2731-40. https:/ doi.org/10.1172/JCI60331.

29. Amato MB, Meade MO, Slutsky AS, Brochard L, Costa EL, Schoenfeld DA, et al. Driving pressure and survival in the acute respiratory distress syndrome. N Engl J Med. 2015;372(8):747-55. https://doi.org/10.1056/NEJMsa1410639.

30. Flori HR, Glidden DV, Rutherford GW, Matthay MA. Pediatric acute lung injury: prospective evaluation of risk factors associated with mortality. Am J Respir Crit Care Med. 2005;171(9):995-1001. https://doi.org/10.1164/rccm.200404-544OC.

31. Reade MC, Finfer S. Sedation and delirium in the intensive care unit. N Engl J Med. 2014;370(5):444-54. https://doi.org/10.1056 NEJMra1208705.

32. Ferguson ND, Cook DJ, Guyatt GH, Mehta S, Hand L, Austin P, et al. High-frequency oscillation in early acute respiratory distress syndrome. N Engl J Med. 2013;368(9):795-805. https://doi.org/10. 1056/NEJMoa1215554.

33. Young D, Lamb SE, Shah S, MacKenzie I, Tunnicliffe W, Lall R, et al. High-frequency oscillation for acute respiratory distress syndrome. N Engl J Med. 2013;368(9):806-13. https://doi.org/10. 1056/NEJMoa1215716.

34. Arnold JH, Hanson JH, Toro-Figuero LO, Gutierrez J, Berens RJ, Anglin DL. Prospective, randomized comparison of high-frequency oscillatory ventilation and conventional mechanical ventilation in pediatric respiratory failure. Crit Care Med. 1994;22(10):1530-9.

35. Pinzon AD, Rocha TS, Ricachinevsky C, Piva JP, Friedman G. High-frequency oscillatory ventilation in children with acute respiratory distress syndrome: experience of a pediatric intensive care unit. Rev Assoc Med Bras (1992). 2013;59(4):368-74. https://doi. org/10.1016/j.ramb.2013.02.007.

36. Moniz M, Silvestre C, Nunes P, Abadesso C, Matias E, Loureiro H, et al. High-frequency oscillatory ventilation in children: a 10-year experience. J Pediatr. 2013;89(1):48-55. https://doi.org/10.1016/j. jped.2013.02.008.

37. Sud S, Sud M, Friedrich JO, Wunsch H, Meade MO, Ferguson ND, et al. High-frequency oscillatory ventilation versus conventional ventilation for acute respiratory distress syndrome. Cochrane Database Syst Rev. 2016;4:CD004085. https://doi.org/10.1002/ 14651858.CD004085.pub4.

38. Gunther A, Siebert C, Schmidt R, Ziegler S, Grimminger F, Yabut $\mathrm{M}$, et al. Surfactant alterations in severe pneumonia, acute respiratory distress syndrome, and cardiogenic lung edema. Am J Respir Crit Care Med. 1996;153(1):176-84. https://doi.org/10.1164/ ajrccm.153.1.8542113.

39. Willson DF, Zaritsky A, Bauman LA, Dockery K, James RL, Conrad D, et al. Instillation of calf lung surfactant extract (calfactant) is beneficial in pediatric acute hypoxemic respiratory failure. Members of the Mid-Atlantic Pediatric Critical Care Network. Crit Care Med. 1999;27(1):188-95.

40. Moller JC, Schaible T, Roll C, Schiffmann JH, Bindl L, Schrod L, et al. Treatment with bovine surfactant in severe acute respiratory distress syndrome in children: a randomized multicenter study. Intensive Care Med. 2003;29(3):437-46. https://doi.org/10.1007/ s00134-003-1650-1.

41. Willson DF, Thomas NJ, Markovitz BP, Bauman LA, DiCarlo JV, Pon S, et al. Effect of exogenous surfactant (calfactant) in pediatric acute lung injury: a randomized controlled trial. JAMA. 2005;293(4):470-6. https://doi.org/10.1001/jama.293.4.470.

42. Ware LB, Matthay MA. The acute respiratory distress syndrome. N Engl J Med. 2000;342(18):1334-49. https://doi.org/10.1056/ NEJM200005043421806.

43. Willson DF, Thomas NJ, Tamburro R, Truemper E, Truwit J, Conaway $\mathrm{M}$, et al. Pediatric calfactant in acute respiratory distress 
syndrome trial. Pediatr Crit Care Med. 2013;14(7):657-65. https:// doi.org/10.1097/PCC.0b013e3182917b68.

44. Willson DF, Truwit JD, Conaway MR, Traul CS, Egan EE. The adult calfactant in acute respiratory distress syndrome trial. Chest. 2015;148(2):356-64. https://doi.org/10.1378/chest.14-1139.

45.• Pediatric Acute Lung Injury Consensus Conference G. Pediatric acute respiratory distress syndrome: consensus recommendations from the Pediatric Acute Lung Injury Consensus Conference. Pediatr Crit Care Med. 2015;16(5):428-39. https://doi.org/10. 1097/PCC.0000000000000350. Summary of PALICC recommendations.

46. Bhattacharya J, Matthay MA. Regulation and repair of the alveolarcapillary barrier in acute lung injury. Annu Rev Physiol. 2013;75: 593-615. https://doi.org/10.1146/annurev-physiol-030212183756.

47. Orwoll BE, Sapru A. Biomarkers in pediatric ARDS: future directions. Front Pediatr. 2016;4:55. https://doi.org/10.3389/fped.2016. 00055 .

48. Orwoll BE, Spicer AC, Zinter MS, Alkhouli MF, Khemani RG, Flori HR, et al. Elevated soluble thrombomodulin is associated with organ failure and mortality in children with acute respiratory distress syndrome (ARDS): a prospective observational cohort study. Crit Care. 2015;19:435. https://doi.org/10.1186/s13054-015-11459.

49. Zinter MS, Spicer A, Orwoll BO, Alkhouli M, Dvorak CC, Calfee $\mathrm{CS}$, et al. Plasma angiopoietin-2 outperforms other markers of endothelial injury in prognosticating pediatric ARDS mortality. Am J Physiol Lung Cell Mol Physiol. 2016;310(3):L224-31. https:/doi. org/10.1152/ajplung.00336.2015.

50. Ciancanelli MJ, Huang SX, Luthra P, Garner H, Itan Y, Volpi S, et al. Infectious disease. Life-threatening influenza and impaired interferon amplification in human IRF7 deficiency. Science. 2015;348(6233):448-53. https://doi.org/10.1126/science.aaa1578. Whole exome sequencing of a healthy child who acquired severe PARDS revealed a putative genetic cause of susceptibility.

51. Shortt K, Chaudhary S, Grigoryev D, Heruth DP, Venkitachalam L, Zhang LQ, et al. Identification of novel single nucleotide polymorphisms associated with acute respiratory distress syndrome by exome-seq. PLoS One. 2014;9(11):e111953. https://doi.org/10.1371/ journal.pone. 0111953.

52. Calfee CS, Delucchi K, Parsons PE, Thompson BT, Ware LB, Matthay MA, et al. Subphenotypes in acute respiratory distress syndrome: latent class analysis of data from two randomised controlled trials. Lancet Respir Med. 2014;2(8):611-20. https://doi.org/ 10.1016/S2213-2600(14)70097-9.

53. Sly PD, Nicholls PK, Berry LJ, Hantos Z, Cannizzaro V. High tidal volume ventilation does not exacerbate acid-induced lung injury in infant rats. Respir Physiol Neurobiol. 2013;189(1):129-35. https:// doi.org/10.1016/j.resp.2013.07.013.

54. Schouten LR, Helmerhorst HJ, Wagenaar GT, Haltenhof T, Lutter $\mathrm{R}$, Roelofs JJ, et al. Age-dependent changes in the pulmonary reninangiotensin system are associated with severity of lung injury in a model of acute lung injury in rats. Crit Care Med. 2016;44(12): e1226-e35. https://doi.org/10.1097/CCM.0000000000002008.

55. Yehya N, Thomas NJ. Relevant outcomes in pediatric acute respiratory distress syndrome studies. Front Pediatr. 2016;4:51. https:// doi.org/10.3389/fped.2016.00051.

56. Santschi M, Jouvet P, Leclerc F, Gauvin F, Newth CJ, Carroll CL, et al. Acute lung injury in children: therapeutic practice and feasibility of international clinical trials. Pediatr Crit Care Med. 2010;11(6):681-9. https://doi.org/10.1097/PCC. 0b013e3181d904c0.

57. Bronicki RA, Fortenberry J, Schreiber M, Checchia PA, Anas NG. Multicenter randomized controlled trial of inhaled nitric oxide for pediatric acute respiratory distress syndrome. J Pediatr. 2015;166(2):365-369 e1. https://doi.org/10.1016/j.jpeds.2014.10. 011. 